\title{
Digital Capitalism: Logic of Capitalism Practice in the Context of Communication Technology in Industry 4.0
}

\author{
Yudhi Mahatma ${ }^{1, *}$ Irwansyah $^{2}$
}

\author{
${ }^{1}$ Universitas Indonesia \\ ${ }^{2}$ Universitas Indonesia \\ "Corresponding author.Email: yudhi.mahatma@ui.ac.id
}

\begin{abstract}
Digitalization is a certainty. Digitalization has become the main communication requirement in the Industrial Revolution 4.0, and the world is experiencing fundamental changes in human ways of living and working. Relations between humans have also significantly changed. In the previous era, information was loaded and exchanged in analog form; today, it is communicated by digital means. Individuals create networks that are interconnected through digital technology on the internet. Information has become the glue of the networked society. Individuals must join the network if they want to stay connected with other parties. A central priority in the Industrial Revolution 4.0 is avoiding being left behind by the progress of the communications technology industry. However, as members of the networked society, we have the right to question the referral and future direction of the goals of digital technology. This study examines the workings of digital capitalism from the perspective of communication technology in industry 4.0. Using a meta-analytical approach, the article begins with an explanation of some perspectives of digital capitalist concepts, which is then corroborated by findings concerning specific categories in the great narrative of digital capitalism. That analysis is followed by a discussion of the practice of digital capitalism on both the national and global scales and an exploration of future opportunities, including the impacts of digital capitalism in network communities. Humanitarian interests must be at the center of technology such that it belongs to all people and is not monopolized by some parties.
\end{abstract}

Keywords: Digital, Capitalism, Industrial Revolution 4.0, Networks Society, Technology, Communication

\section{INTRODUCTION}

Surfing in the virtual world and enabling connections to data sources in real time have become major activities in the digital technological era. The previous abundance of information in analog form has been supplanted by the development of infinitely expansive digital data marked as bits (binary digits), placed on clouds, and classified as "big data" (Valenduc \& Vendramin, 2017). Digitalization has brought about significant changes in how people looking for information related on how people keep its own existence. During the era of agrarian society, people searched for information by physically traveling and exploring the resources that could meet their needs; however, digital technology enables people to explore the world and gain information by entering a cyber world connected to other information resources
(Schwab, 2016). For example, internet search engines connect users' devices with those of data providers. In the information society, data has become the main resource exchanged between network members (Castells, 2000).

The Industrial Revolution 4.0 has changed on how people work and relate with others (Schwab, 2016). Economic capital alone is not sufficient to enter and participate in the industry. The integration of cyber systems and automation technology has become a central element of industry 4.0, which emerged when computation technology brought society to the phase of digitally-based industry. Communication and connection among parties is a major activity in the industry 4.0 era.

Human activities in searching and producing digitally-based data and information have become ways 
to convert knowledge into economic capital. Interactions between people and data resources effect the conversion strategy and generate economic benefits. Participation is converted such that it increases the economic value of a set of data from users' participation in online activities (Schwab, 2016). Economic and social exploitation is a notable consequence when users engage in interactions while connected to the cyber world (Fisher, 2010), and some parties have become service providers that fuel these interactions. Economic activities are involved in every technological development, including digital technology connected through the internet.

The structure of digital activities can be analyzed from the perspective of the Marxist concept of work value; however, there is an alternative framework for creating the value of practices in prosumer practices, in which internet users are also the data providers (Arvidsson \& Colleoni, 2012). In the alternative framework, the understanding of value creation outside the formal work system is based on the capacity to start and maintain networks of affection, and value realization is derived from reputation based financial economic. This model explains the creation of value and appropriation in the context of networked prosumer platforms. Christian Fuchs (2014a) applied Marxian class analysis to explain the general concept of "information capitalism," which he specifically related to new forms of media such as Google, YouTube, Myspace, and Facebook. Fuchs concluded that such platforms are highly dependent on free labor, as their production processes generally provide no salary, with the result being that information capitalism entails an unprecedented scale of exploitation of "knowledgeable, paid, and unpaid workers" (Fuchs, 2014b).

This study presents a literature review of capitalist practices in the context of the communication technology industry. The article examines the logic of capitalism that leads to economic exploitation, which is considered an extension of people's ability to solve problems related to economics and survival, and it also considers opportunities for equality in technological development. Both users and data providers are considered participants in converting user activity into large collections of data to reap economic benefits.

This study reviews initial understandings of digital capitalism based on previous studies. Concisely, the concept of digital capitalism is raised to examine the gap among social classes in the context of the creation of industrial technology as well as the corporation. The digital capitalism approach has been explored in a series of frameworks, such as informational capitalism (Castells, 1996), cybercapitalism (Schiller, 2000) (Mosco \& Schiller, 2001), technocapitalism (Kellner, 2002), and virtual capitalism (Dawson \& Bellamy Foster, 2000). Initial conceptualizations aimed to understand social complexity and the relationship between new technologies and capitalism. Social complexity derives from the multiple dimensions encompassed by the relation between capitalism and new technology, including social and political-economic interactions. Specifically, the market-driven policies of Western governments (particularly the United States) have engendered the establishment of a neo-liberal influenced network communication infrastructure fueled by a political-economic transformation of supporting internal corporations and transnational companies in the internet era (Schiller, 2000).

This study uncovers the social irregularities of digital capitalism. Although most reviews of capitalism focus on its structural aspects, this work will consider the agent dimensions as informed by Jean Baudrillard's (1998) thoughts of the consumption society. The resulting understanding shows the importance of analyzing the social, political, and economic dynamics of today's internet as well as engaging in critical reflection on the challenges facing democracy (Curran, 2012). The establishment and strengthening of digital capitalism are related to the emergence of the World Wide Web as a consumer medium (Schiller, 2000).

\section{LITERATURE REVIEW}

\subsection{Methodology}

A literature review approach comprises a series of activities such as collecting library data, reading and recording, and managing research material (Danial \& Warsiah, 2009). A literature review aims to develop both theoretical and practical aspects of the research topic.

By conducting literature reviews, researchers gain broader and deeper insights into the problem under study. The author conducted this literature review after determining the topic of the study and the formulation of the problem based on a consideration of the facts of the field and how to collect the necessary data. The data used herein derives from books, journals, journalistic reports, scientific articles, and other literature that discuss the concepts being studied.

\subsection{Conceptual Review}

\subsubsection{References on Capitalism}

This article's discussion on capitalism is informed by Marxist frameworks. Specifically, the study applies Marxist ideas on capitalism as elaborated by David Harvey (2010). In order to obtain an understanding of capitalism and society, we also need to understand related issues on space and geography as well as time, such as work time and the theory of work value.

Although not specifically called as techno-skeptics, Harvey criticized the cellular media for promoting images that manipulate people's needs and create fake 
awareness (Harvey, 2010). Rather than asking users for their contributions, capitalist mobility enables corporations to make people work almost any time and anywhere, which breaks the boundary between spare time and the workforce under the exploitative conditions of mobile phone production in international divisions of work capitalism.

Work convergence and spare time would be less problematic if working activity could become more fun, social, and independent. Companies' desire for productive workforces has resulted in the absorption of spare time so workers can generate more value. Harvey's (2010) discussion of communication facility based on Marx's works analyzed this issue as a spatial attribution. Information and communication technology, including computers, play an important role in the acceleration of commodity space-time circulation (Harvey, 2010). Computers and digital networks are not only organizers of data and information circulation, they also serve as tools to produce information products. Computers and digital networks have become internal and external platforms for communication companies. Whereas vehicles transport people, computer networks transport product information and communication waves. A computer is a universal engine that is used as a production, circulation, and consumption tool

\subsubsection{Scope of Digital Activity}

Analog systems provide data in the form of atoms, like writing on paper or in books, voices from membrane vibrations, the beam of light from an incandescent lamp, and the touch sensed by the nerves of the skin. However, bits are the smallest atomic elements of information; they have no color, size, or weight and they can move at the speed of light. Digital activities have supplanted the analog signal with the digital signal. Information in the form of text, voices, and images, including knowledge or human cognition, are embedded in digital signals consisting of bits embodied in 1 and 0 units (Negroponte, 1995). Negroponte (1995) pointed out the study of a radical new culture that has arisen in the middle of graphic computers and human communication in the interactive multimedia era.

It can be said that the information revolution was marked by the shift from atom to bit form, especially in the information industry. Sound, static images, or videography can be translated and widely distributed as bit structures. Human-information relations have undergone radical change (Negroponte, 1995). In digital media, not only conversion or copying can be done easily, people are also able to send information from one medium to many media en masse. As users, humans interact and interpret the information through the interface medium. At this point, human communication patterns have also changed drastically, some even struggle to tie the relation with other users. However, human curiosity has bridged analog and digital knowledge. For instance, virtual reality (VR) gives users the experience that they are also "there" even though they remain in a different time and space. Digital technology enables people to overcome time and space limitations in the context of their relations with other people (users).

In the information era, mass media have become wider and smaller at the same time. In the postinformation era, we often only have audiences. Everything is made to order and information is personalized. The post-information era will eliminate geographic boundaries in the same way that hypertext eliminated the delimitation of printed pages (Orihuela, 2003). In the post-information age, the concept of address has acquired a new meaning, as you can live and work in on one or more location. Addresses have taken on a virtual form, such as email.

Digital technology in the form of the internet and social networking has changed the paradigm of public communication dynamics that prevailed in the analog mass media environment. Many communication challenges for traditional media have emerged in the digital era, such as new relations with the public (interactivity), a new language (multimedia) and new grammar (hypertext), as well as real time relations in time and space (real time) (Orihuela, 2003). Globally, the process of digitalization can be understood as a massive transformation from the classic mass media model to a new media paradigm: users have become central processers of communication, data in the form of content is the identity of media, multimedia is the new language, real time is the only time, hypertext is the grammar, and knowledge is the new name of information.

Gordon E. Moore, co-founder of the United Statesbased microchip maker Intel, elaborated Moore's law in relation to the storage and processing of computation in digital data technology. Moore's law predicts that the amount of transistors in an IC (integrated circuit) will double approximately every two years and has proven to be an accurate estimation of the progress of computing technology (Reichardt, 2006). In industrial contexts, the data storage has become as small as a fingernail in the shape of a MicroSD, which has 1,000 times the capacity of early storage devises (4 gigabytes and more). The computation ability previously restricted to huge desktop devices is now inside smartphones (Melnikov \& Semenyuk, 2014).

Today, computation ability is not only owned by large companies, as technological democracy makes it possible for individuals to become more than passive users who fully depend on information from data providers. Individual users have become producers of data known as user-generated content (UGC), as seen in social media such as YouTube, Facebook, Twitter, 
Instagram, and web-logs (blogs) (Duffy, 2015). Advances in communication and information technology have generated a convergence in the media industry (Tapsell, 2015). Now, conventional media (TV, radio, newspaper) has established a bigger hold in new media platforms and multiplatforms. Thus, a technology convergence has occurred whereby old and new platforms meet on a single platform due to the digitalization of media content.

\section{FINDING AND DISCUSSION}

In simple terms, digital capitalism refers to capitalism through internet connectivity. The concept of cyberspace was initially developed by government entities (government bodies, education institutions, military contractors); however, it is now primarily a tool for profit oriented corporate users rather than to increase the prosperity of its users. Mining digital data used for social activities to connect people, family, and friends has become an economic activity and so does with personal life. Services such as reading the news, listening to the music, interacting with friends, information sharing, making purchases, and so on have become faster through digitalization.

There is no single theory that can elaborate the development of digital capitalism. The phenomenon has walked slowly but surely from the 1990s to the present day. Two events can be considered to represent background of digital capitalism development. First was the Fordism phenomenon, which emerged when Henry Ford became the first mass automaker during the Industrial Revolution and introduced the largest capitalism facility to-date during the 1950s. Ford introduced workforce specialization to first produce separate spare-parts and then combine them through mass assembly so that Ford could produce a large amount of cars at a single time. As a result, the auto market was monopolized by his company. Capitalism homogenized society's consumption patterns by introducing the mass production wave, and bidding logic came to dominate the automotive production market. This capitalist practice gained critics due to inequalities that generated cynicism among the working class against the capital owners. Producers maintain the consumption pattern by slipping in added value to the things they produce through advertising or bidding logic (Baudrillard, 1998).

Capitalism entered the digital platform when the World Wide Web programming phenomenon was developed by Tim Berners-Lee (Adida, 1997). A radical transformation occurred with the shift from Web 1.0 technology (read, consult, surf, and search) into Web 2.0 (read-write, participation/collaboration, interactive, network as platform). The main concern of Web 2.0 technology is users' participation (O'Reilly, 2005); users give data input to a website address, with the main implication being that the web will have more data and not depend on data input from technicians or programmers. Whereas the web preciously depended on the centralization of data sources, Web 2.0 technology enables users to provide data using no particular computer programming language.

With the idea network as a platform providing space to collaborate, there is a need for users to keep consuming the technology. In addition to obtaining information from web providers, interaction in the cyber world has become a need. Examples of Web 2.0 operations are applications that users do not have to buy software to operate, such as Wikipedia and Google. Users can directly input their queries using daily language. Keywords are critical elements of this technology because the user can specify the displayed data on a platform. Data input activity in the form of keywords by users has become information fuel that is processed by websites like Google. A set of keywords from users is classified and accommodated to become a set of big data. The experience engenders and enhances the users' dependence on the website because the users' data searching activities yield results that are wanted by the users. However, the data input from users' activities have economic value, which is offered to advertisers. The same thing also happens on social media sites such as Facebook, Instagram, Twitter, and so on.

The implication of users' contribution to networks through web activity has become the main tool for market dominance in the Web 2.0 era (O'Reilly, 2005). Ensuring users' continued involvement is the primary operation of managing Web 2.0. Pleasant and fun user interfaces and experiences are major priorities for Web 2.0-based site developers. The implication is that the users conduct their activities on a website not because of any need but rather due to the desire to feel the amazing experience and display with which they are presented. Meanwhile, the websites' owners continue mining data in the form of information input from users that sign in to the network. Interaction with other users also extends engagement with a website.

\subsection{Data and Information as Commodities}

Commodities are the fundamental drivers of capitalism (Marx, 1976). Critical analysis of commodities leads to an understanding of the commodification of media. The media that becomes a medium is now a producer and manager of information. Because data is the main fuel in the relations between parties in networking communities (Schneider \& Castells, 1997), information has become a unique commodity. Information can be easily collected, copied, and distributed. Data have high initial production costs; however, the costs of copying and distribution are low. Data production entails high risk and uncertainty about whether or not the data can be sold (Fuchs, 2017). The 
logic used in this basic form of capitalism is transactional logic, and data is the exchange tool. Rather than users having an equal bargaining position, the power is mainly owned by the manager or owner of the digital platform or website. Users remain a lower class, namely consumers, although they still supply materials in the form of data for website managers. The user is a free labor class in the relationship.

The wealth of information is the main capital in digital capitalism. The sheer abundance of information requires a specific strategy to manage it and elevate the website from a mere digital waste dump. Data management includes a strategy of transferring functions or the commodification of shared rules regarding intellectual property rights and copyrights, namely the initial agreement in the form of the user's approval of website usage. Rules that become a joint legal umbrella are made by web managers, including approval of privacy policies. The offered narrative is essentially "using means agreeing" to all the rules contained in the website; however, the construction of joint policies and rules does not necessarily involve user participation. Rather than protecting the users, website managers usually include an offer of approval that the data they obtain from user activities will be used as a database, which means that the users allow the managers to use their information to be retargeted toward them so they remain connected with the website.

Are users aware of the restrictions on their right to know the use of data or information that has been sent to the manager? In most cases, the answer is no! Even if they realize it, prosumers prefer to entertain themselves by staying active on the basis of the interesting user experiences offered by the website managers. Another problem related to privacy is that most digital giants either do not have a strong privacy mechanism or ignore the mechanism. Many privacy issues have emerged on social media websites such as Twitter, Instagram, Facebook, and others (Segura \& Waisbord, 2019). Although the issue of personal data privacy has led to debate, no concrete policies have been developed to regulate this issue.

The next strategy is commodification from access into content in the form of subscriptions whereby the users obtain notification of content updates. Web 2.0 technology allows users to obtain notifications of new data uploaded to the website. If users think they need it, they will provide their virtual addresses (email addresses) in order to obtain personal notifications. The act of providing and obtaining notifications is a strategy to keep users connected to the website. When users are online, they will obtain the notifications and respond to them. Attractive content also keeps users and managers connected on the network.

Commodification of the production, distribution, and consumption of technology includes updating content and algorithms as well as the user interface and experience. Content and distribution are well matched in order to attract users to the website. Although website content is important and interesting for viewers and users, if it does not support massive distribution, users' access to content will become slower. It can be said that the content becomes passive, as in the logic of Web 1.0 technology, whereby content only waits for information seekers rather than actively targeting users.

Commodification of the audience occurs through advertising. Commodities gained from users and their data are generated in targeted online advertisements. The users are obliged to comply with such commodification by their agreement with the shared rules regarding website use, which includes accepting changes in programming languages (algorithms) and making users act as audiences when a website displays commercial content or advertisements. These advertisements are not arbitrarily chosen; rather, their content is adjusted according to users' activity on the website. The computational algorithm has analyzed and reported users' activity to the system, which then independently provides feedback to display the advertisements according to user preferences.

\subsection{The User Interface in the Context of Digital Capitalism}

The creation of the World Wide Web was a turning point in the history of the internet that radically changed the way information is accessed, shared, and organized around the world (Curran, 2012). Network sites serve as platforms to build and form "user-interfaces" that provide a convenient way for owners to manage and access data and distribute it across computer networks.

The inventor of the World Wide Web, Tim BernersLee, has always been committed to social welfare and imagined the web as a "universal medium" for information sharing, i.e., a form of media that was not primarily defined by commercial interests (Berners-Lee, 2014). Throughout the 1990s, Berners-Lee's original project was overthrown by the aggressive commercialization of the web (Curran, 2012), which strengthened company control over content as well as facilitating new practices of corporate supervision and exploitation. The entrenchment of web commercialization was made possible through a series of technological advancements and web developments, such as the establishment of Google's monopoly in the search engine field. Tim O'Reilly, the founder of O'Reilly Media and the person who popularized Web 2.0 and open source terminology, said that the early 2000s had seen the development of different types of early web versions (O'Reilly, 2005). The newer forms were no longer based on hypertext networks, but rather on the coproduction of information, social networks, and utilization of the collective intelligence of its users to 
create value. "Participation," "interactivity," and "usergenerated content" are terms used in business, popular publishing, and academics to determine these later developments in web technology.

The potential of new technologies for interactive features has offered unprecedented possibilities for user involvement, creativity, and collaboration. Nonetheless, this system is still far from democratic because it does not offer opportunities for collaboration between owners and web users. Web 2.0 technology actually strengthens new forms of capitalist exploitation and supervision (Fuchs, 2007). Veronica Barassi (2015) argued that the digital discourse around Web 2.0 works as a form of capitalist justification and legitimacy as well as an amplifier of the new spirit of capitalism.

\subsection{Globalization Dilemma and Technology Opportunities}

The progress of the communication technology industry that enables humans to be connected globally through the internet and digital media comes with a dilemma as well as a challenge that must be addressed immediately. Christian Fuchs (2007) mentioned a number of concepts that could be subjects of more indepth study: internet dialectics; digital capacity; commodification and forms of digital media commodities; labor, surplus value, exploitation, alienation, and class in the digital era; globalization and the internet; ideology and the internet; class struggle in digital media; shared digital; digital public space; digital media and socialism; and the aesthetics of digital media.

Technology development opportunities are still wide open. Narratives related to technology that makes people prosperous should be echoed not only at the conceptual level, but also in practical ways. Each pattern illustrates the repetition of problems in the community. It is important to elaborate solutions to these problems so that the community can implement them appropriately. The communications technology industry is increasingly driven by the abundance of data. For competitive advantage, they try to have unique data sources and make themselves difficult to recreate. Competitive advantages in the internet and digital media depend on the degrees to which users add data. Software and website technology can always develop room for fair participation as well as reduce or eliminate gaps between platform owners and developers and the users who keep supplying them with data.

\section{CONCLUSIONS}

The narrative of the advance of communication technology is being shaped by capitalist logic. Ideas of equality for the common good as proposed by great thinkers such as Karl Marx, Friedrich Engels, and others seem restricted to world thought, whereas capitalism has always remained an inevitable fact. Capitalism is a major force in digitalization, which has enabled the extension of humans' ability to overcome the problems of space and time. The development of the digital-based communication technology industry has strengthened the formation of a networked society in which information is a form of capital and the aim is for each individual to stay connected in the network. In information communities, data is a commodity and an exchange value to establish relations with other people and fulfill the basic human needs of self-defense and survival. Some parties develop digital platforms to enable users to communicate and become connected.

The critiques elaborated in this study relate to deceptions underlying the ease and speed of the spread allowed by digital giants. For example, Facebook generates nothing from users who only read interesting uploads without engaging in "click" activities; content is created when users search for topics that suit their tastes or press the "like" button, react, or comment on uploads. Thus, the more uploads become viral the more opportunities are generated for interactions with website readers, including comments and reactions. Moreover, the opening of the world of memes has allowed users to express their creative ideas regardless of whether they can harm other people. As more viral news uploads on their walls to attract visitors, the search engines gain more data through users' searches from the upload.

Other critiques discussed in the article are related to unresolved privacy issues associated with the rules of website use. Digital capitalism cannot be ruled out as an irrelevant social force impacted by well-known concepts like class equality, ownership of personal assets, and even socialism. Most people's ways of life promote competition without monopoly and efficiency, but rather through different media. This is important for producers and consumers alike. However, the negative impacts of its growth should be examined further to prevent criminal acts that begin with the exchange of data with minimal essential truths that can disrupt the democratic process. A number of mechanisms need to be developed as filters to protect the public, and it is important to enhance digital literacy or education so the communication between parties occurs on the basis of awareness and mutual agreement. 


\section{REFERENCES}

[1] Adida, B. (1997). Weaving the web. IEEE Internet Computing. 1(4), 91-93. https://doi.org/10.1109/4236.589197

[2] Arvidsson, A., \& Colleoni, E. (2012). Value in informational capitalism and on the internet. Information Society, 28(3), 135-150. DOI: https://doi.org/10.1080/01972243.2012.669449

[3] Barassi, V. (2015). Activism on the Web. Everyday struggles against digital capitalism. Routledge, 2015. DOI: https://doi.org/10.4324/9781315870991

[4] Baudrillard, J. (1998). The Consumer Society: Myths and Structures. London: SAGE Publications Inc.

[5] Berners-Lee, T. (2014). Web for Real People, 2005.

[6] Castells, M. (1996). The rise of the network society. The information age-Malden, Mass. In British Journal of Sociology, 1, 480.

[7] Castells, M. (2000). The information age: The rise of the network society. Economy, Society and Culture, 1, 407-460).

[8] Curran, J. (2012). "Rethinking Internet History" In Misunderstanding the Internet. (J. C. N. F. Des Freedman, Ed.). London New York: Routledge.

[9] Danial, \& Warsiah. (2009). Metode Penulisan Karya Ilmiah. Bandung: Laboratorium Pendidikan Kewarganegaraan UPI.

[10] Dawson, M., \& Bellamy Foster, J. (2000). Virtual Capitalism In Capitalism and the Information Age: The Political Economy of the Global Communication Revolution. New York: Monthly Review Press.

[11] Duffy, A. (2015). The road more travelled: How user-generated content can lead to homogenized travel journalism. Continuum, 29(6), 821-832. DOI: https://doi.org/10.1080/10304312.2015.1073686

[12] Fisher, E. (2010). Media and New Capitalism in the Digital Age. Media and New Capitalism in the Digital Age. New York: Palgrave Macmillan US. DOI: https://doi.org/10.1057/9780230106062

[13] Fuchs, C. (2007). Internet and Society: Social Theory in the Information Age. Internet and Society: Social Theory in the Information Age. DOI: https://doi.org/10.4324/9780203937778

[14] Fuchs, C. (2014a). Digital Labour and Karl Marx. New York: Routledge.
[15] Fuchs, C. (2014b). Digital prosumption labour on social media in the context of the capitalist regime of time. Time \& Society, 23(1), 97-123. DOI: https://doi.org/10.1177/0961463X13502117

[16] Fuchs, C. (2017). Marx's capital in the information age. Capital and Class, 41(1), 51-67. DOI https://doi.org/10.1177/0309816816678573

[17] Harvey, D. (2010). A Companion to Marx's Capital. London: Verso.

[18] Kellner, D. (2002). Theorizing globalization. Sociological Theory, 20(3), 285-305. DOI: https://doi.org/10.1111/0735-2751.00165

[19] Marx, K. (1976). Capital: A Critique of Political Economy, vol.1. Capital: A Critique of Political Economy. London: Penguin Books. DOI: https://doi.org/10.4324/9781912282258

[20] Melnikov, A. V., \& Semenyuk, E. P. (2014). The information revolution and the modern printing industry. Scientific and Technical Information Processing, 41(1), 1-11. DOI https://doi.org/10.3103/S0147688214010031

[21] Mosco, V., \& Schiller, D. (2001). Continental Order?: Integrating North America for Cybercapitalism. Lanham, Md.: Rowman \& Littlefield.

[22] Negroponte, N. (1995). Being Digital. New York: Alfred A. Knopf.

[23] O'Reilly, T. (2005). What Is Web 2.0: Design patterns and business models for the next generation of software, Communications \& Strategies, (1), 17.

[24] Orihuela, J. L. (2003). eCommunication: The 10 paradigms of media in the digital age. II A20 COST Conference.

[25] Reichardt, R. (2006). Moore's law and the pace of change. Internet Reference Services Quarterly, 11(3), 97-109. DOI: https://doi.org/10.1300/J136v11n03

[26] Schiller, D. (2000). Digital Capitalism: Networking the Global Market System. Cambridge, Mass: MIT Press.

[27] Schneider, P. A., \& Castells, M. (1997). The information age: Economy, society and culture volume I: The rise of the network society. Journal of Marketing, 61(4), 96.

[28] Schwab, K. (2016). The Fourth Industrial Revolution. Geneva: World Economic Forum.

[29] Segura, M. S., \& Waisbord, S. (2019). Between data capitalism and data citizenship. Television \& 
New Media, 20(4), 412-419. DOI: https://doi.org/10.1177/1527476419834519

[30] Tapsell, R. (2015). Platform convergence in Indonesia: Challenges and opportunities for media freedom. Convergence, 21(2), 182-197. DOI: https://doi.org/10.1177/1354856514531527
[31] Valenduc, G., \& Vendramin, P. (2017). Digitalisation, between disruption and evolution. Transfer: European Review of Labour and Research, 23(2), 121-134. 